\title{
Social capital in the viewpoint of members of the boards of trustees of primary schools in Assiut governorate countryside, Egypt
}

\author{
Rashed M. G. ${ }^{a}$, Ahmed M. H. ${ }^{a}$, Ibrahim A. A., Ali A. M. ${ }^{a}$, Ahmed N. I. A. ${ }^{\text {a,b* }}$ \\ ${ }^{a}$ Rural Sociology \& Agriculture Extension Department, Faculty of Agriculture, Assiut University, Assiut, Egypt \\ ${ }^{b}$ Higher Institute for Agricultural Cooperation and Extension, Assiut University, Assiut, Egypt
}

\begin{abstract}
The concept of social capital occupied an important place in the era of globalization as a result of the failure of development efforts witnessed in the second half of the last century and the inability to achieve justice, to emphasize its scientific value as a civilized economic effort that went beyond the adversity of development, growth and the inequitable distribution of wealth. In this context, the current research sheds light on the diagnosis of the reality of social capital in the primary school, and how it is formed under the factors linked between the school and members of the Board of Trustees and parents, and the role it plays in guiding and facilitating the educational process, and then achieve the desired scientific knowledge of the educational system. The present research methodology is based on the sample survey methodology applied to 36 members of the Board of Trustees distributed in 5 selected primary schools from the centers of Abutieg, Sahel Selim, Assiut, Qusiya and Abnoub in Assiut governorate, Egypt. Perhaps the most prominent findings of the study are that those with a medium knowledge of the concept of social capital accounted for the majority, while the low and high literacy rate did not exceed a quarter of the total respondents, and that the prevailing trend for the four dimensions of social capital was characterized by the average for the dimension of tolerance, diversity, and acceptance of the other. It had a tendency towards the average for the dimension of mutual trust, and was characterized by the average for the dimension of the network of social relations, coming after the collective and voluntary work to be the predominant trend on the high. Of course, this reality of social capital drives towards improving the relationship between the school and the surrounding community, which leads to improvement of the educational process in the primary education system.
\end{abstract}

* Corresponding author: Ahmed N. I. A.,

E-mail address: nageh12345678977@ hotmail.com 


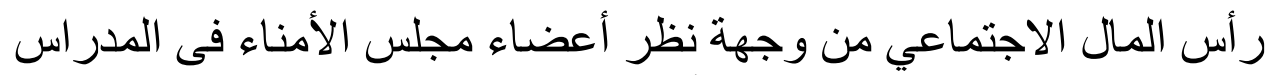 الإبتدائية بريف محافظة أسيوط بجمهورية مصر العربية الإية العناء
}

\author{
محمد جمال الدين ر اثد' ، مصطفى حمدى أحمد'، أحمد عبد اللطيف ابر اهيم' ، عبد الصمد محمد على' ، ناجح اسماعيل عبد الحكيم '،r \\ 'قسم المجتمع الريفي والإرشاد الزراعي ، كلية الزراعة ، جامعة أسيوط ، أسيوط ، جمهورية مصر العربية

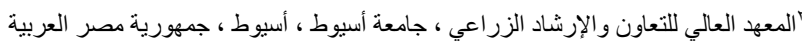

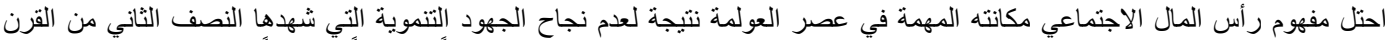

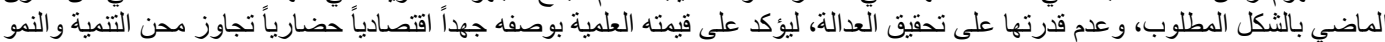

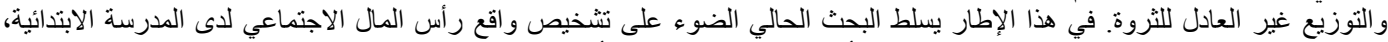

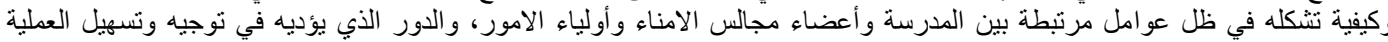

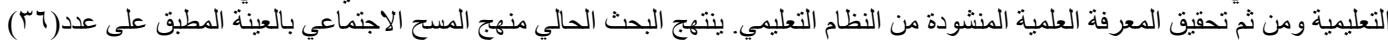

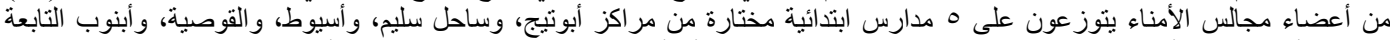

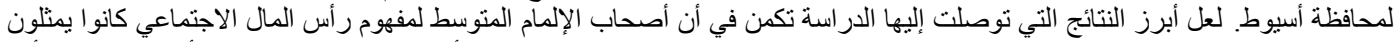

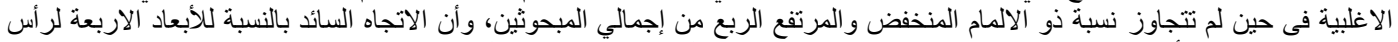

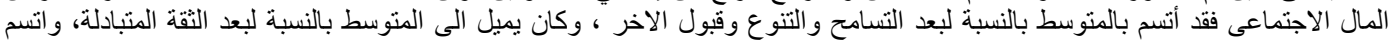

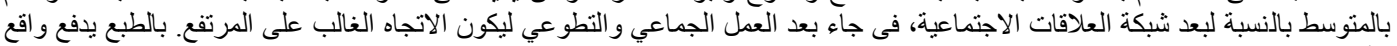

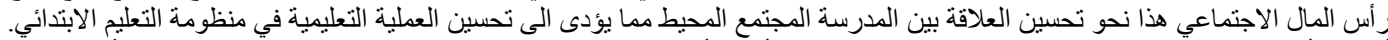

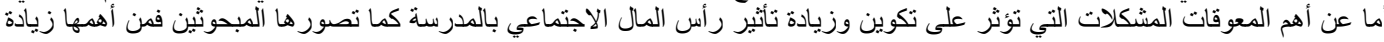

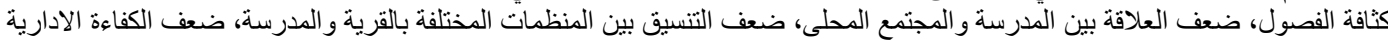

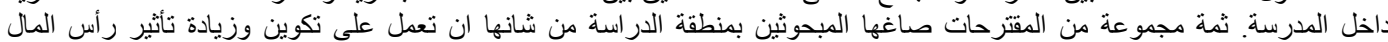

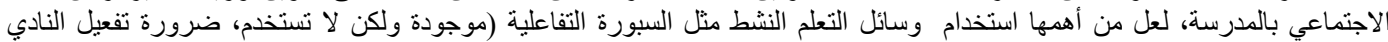

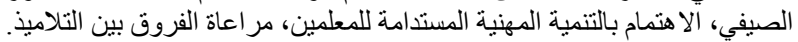

كلمات دالة: ر أس المال الاجتماعي ، العولمة ، المدرسة الابتدائية، الكفاءة الادارية ، السبورة التفاعلية. 


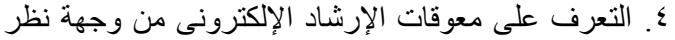

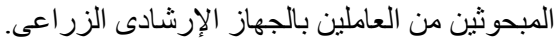

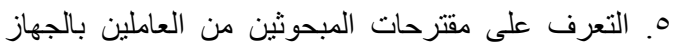

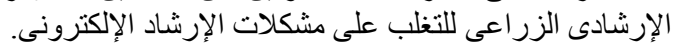

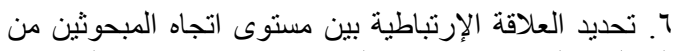

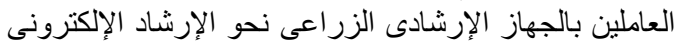

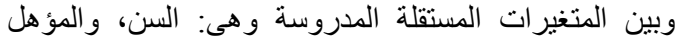

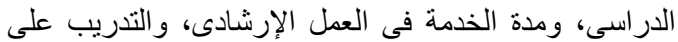

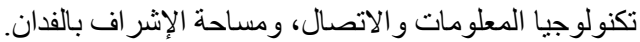

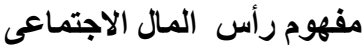

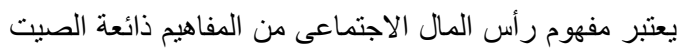

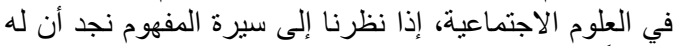

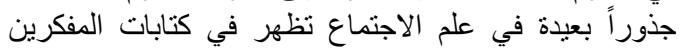

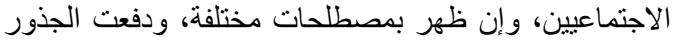

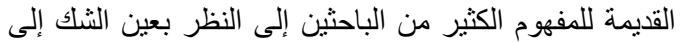

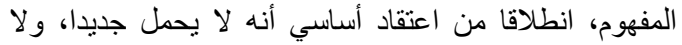

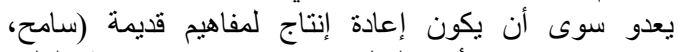

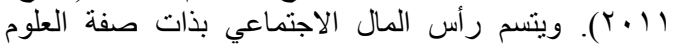

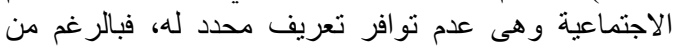

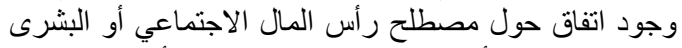

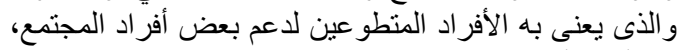

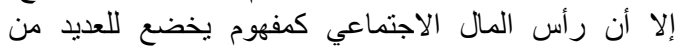

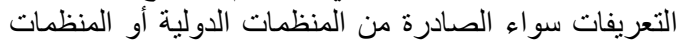

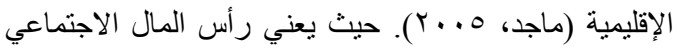

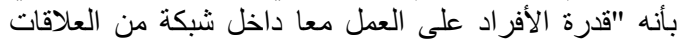

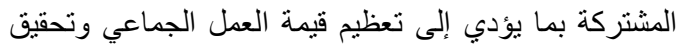

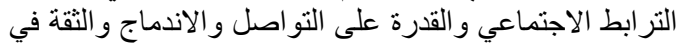

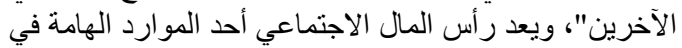

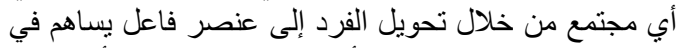
تحقيق التتمية المجتمعية، كما أن هنالك حاجة لتنمية رأس المبل المال

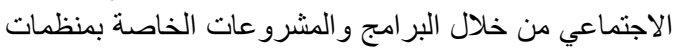

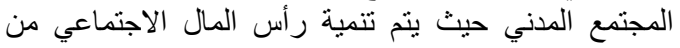

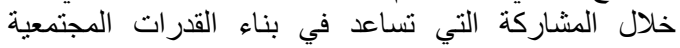

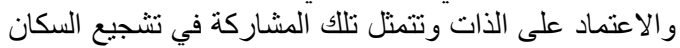

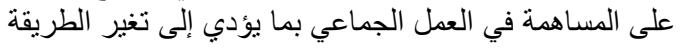

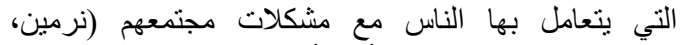

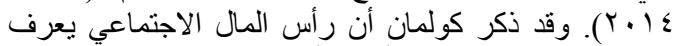

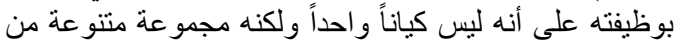

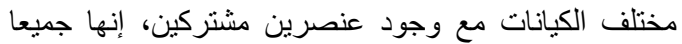
تتألف من بعض جو انب البنى الاجتماعية وتسهل أفعال معينة التينة

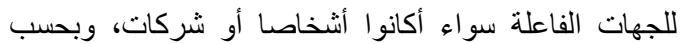

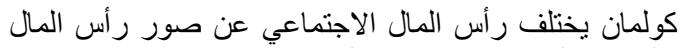

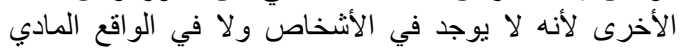

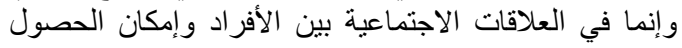

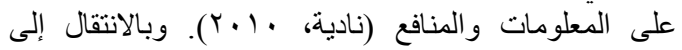

\section{المقدمة و المشكلة البحثية}

يحتل مفهوم رأس المال الاجتماعي مكانة بارزة في ادبيات

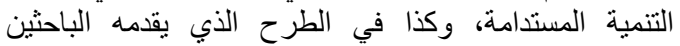

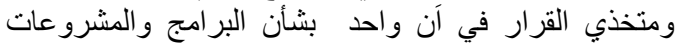

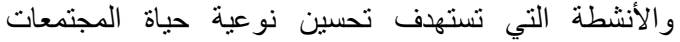

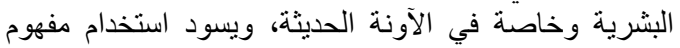

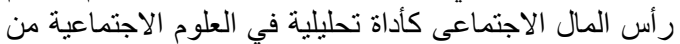

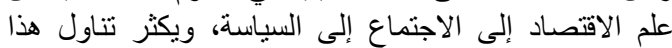

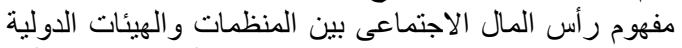

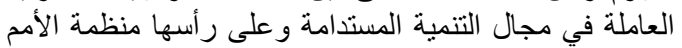

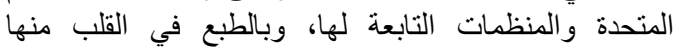

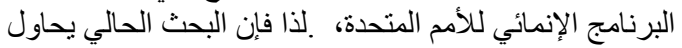

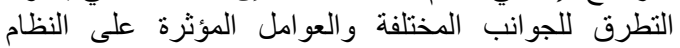

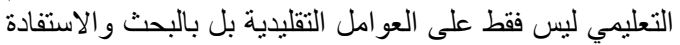

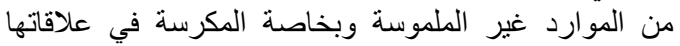

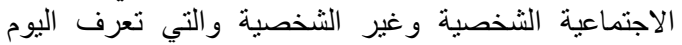

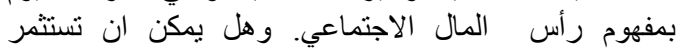

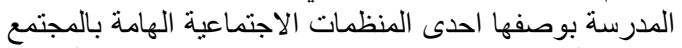

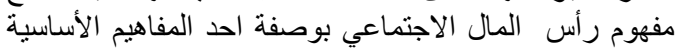

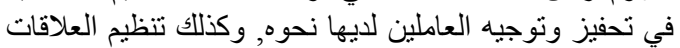

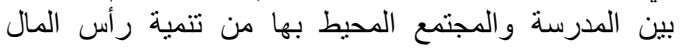

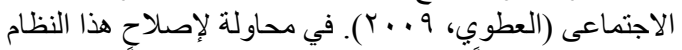

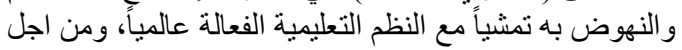

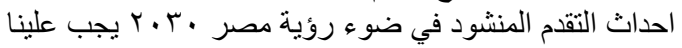

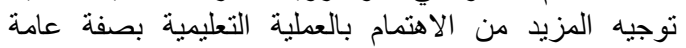

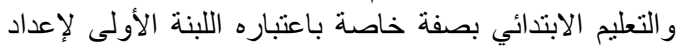

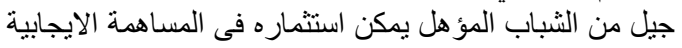

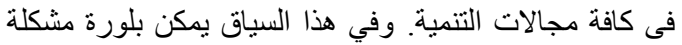

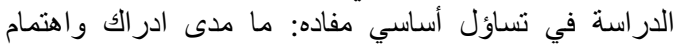
أعضاء مجالس الامناء لمفهور رأس رأس المال الاجتماعي للمدرسة الابتدائية بريف محافظة أسيوط؟.

\section{أهداف البحث}

يستهدف هذا البحث بصفة رئيسية تحديد اتجاهات العاملين بالجهاز الإرشادى الزراعى نحو الإرشاد الإلكترونى بمحافظة أسيوط:

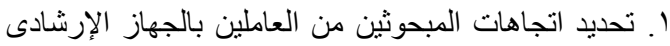

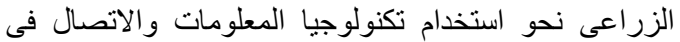
العمل الإرشادى الزر اعى بمحافظة أسيوط . الزئ.

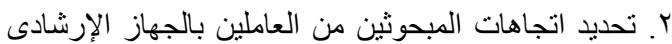

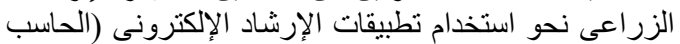

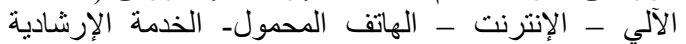
الإلكترونية) فى العمل الإرشادى الزئر اعى بمحافظة أسيوط.

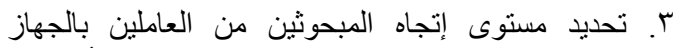
الإرشادى الزراعى نحو الإرشاد الإلكترونى بمحافظة أسيوط. 
رأس المال الاجتماعي، ومن الملاحظ أن هذه الدراسات قد

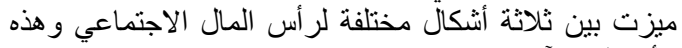
الأشكال كالآتي: تانلة

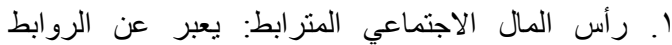

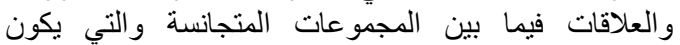

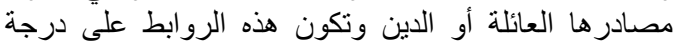
عالية من الثقة و التضامن فيما بين الأفراد الدادي

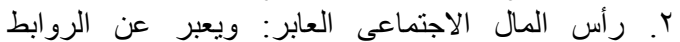

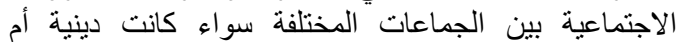

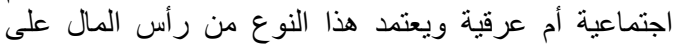

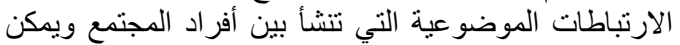
من خلالها تكوين شبكة من العلاقات الاجتماعية.

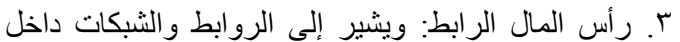

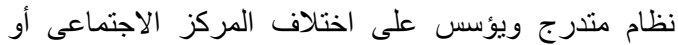

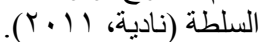

\section{مصادر رأس المال الاجتماعي}

اختلفت الآراء حول مصادر رأس المال الاجتماعي فيما بين الماني

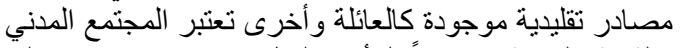

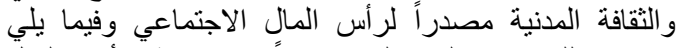
توضيح للمصادر التي تلعب دوراً في تلتمية رأس المال الاجتماعي وهي : الإحئ

ا. الدين: يعتبر الدين من أهم مصادر تكوين رأس الماعي المال

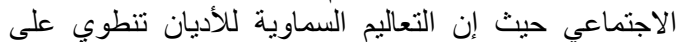

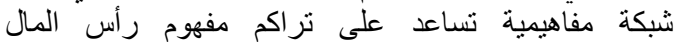

الاجتماعي. r. الأسرة: تعد الأسرة المكون الرئيسي لرأس المال

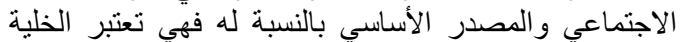

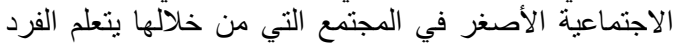

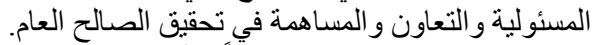

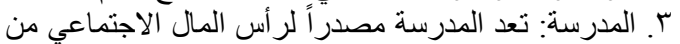

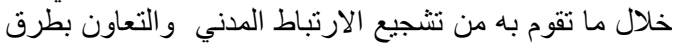

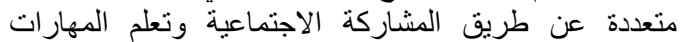

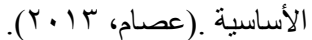

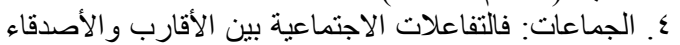

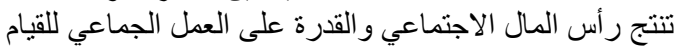
بخدمة عامة . بل المعال

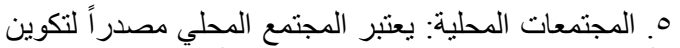

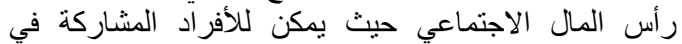

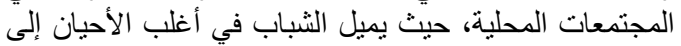

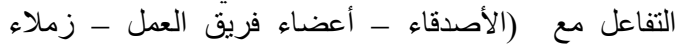

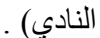
T. القطاع العام: يختص القطاع العام بالدولة ومؤسساتها و التي

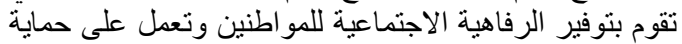

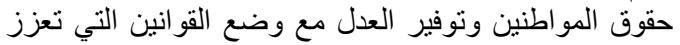
ذلك. V. الثركات: يعتمد تكوين رأس المال الاجتماعي في

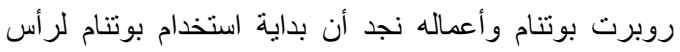

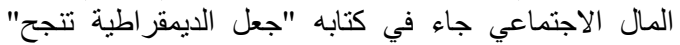

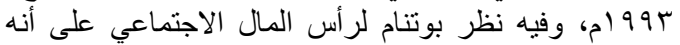

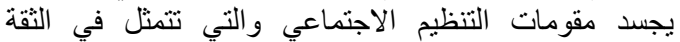

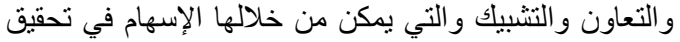

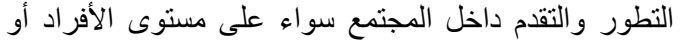

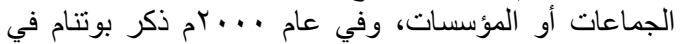

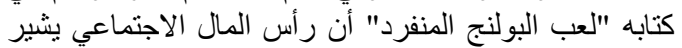

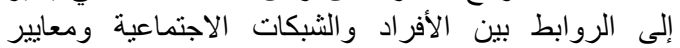

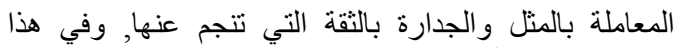

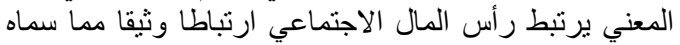

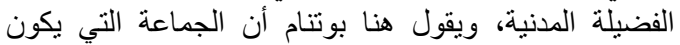

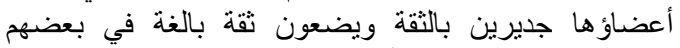

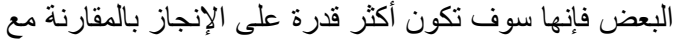

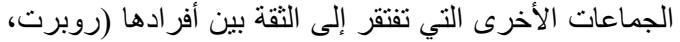

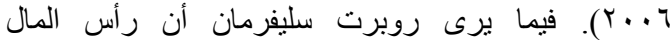
الاجتماعى على أنه علاقة من الثقة المتبادلة الناشئُة من القيم الثيان

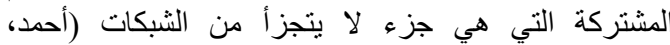

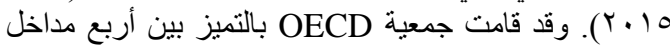
أساسية لتناول دراسة هذا المفهوم وهي:

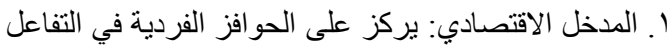
مع الآخرين والرغبة الذاتية في الاستثمار في رأس المال

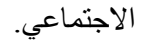
r. مدخل العلوم السياسية: بركز على دور المؤسسات السياسية

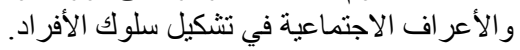

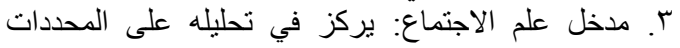

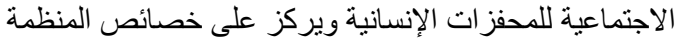

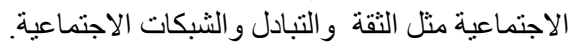

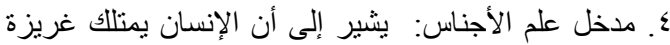
أساسية تتمثل بالرغبة في المشاركة والتعان التعاون مع الآخرين.

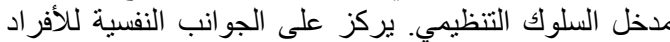
ودور ها في تشكيل السلوك الجماعي المثمر المبني على الثى الثقة

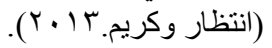

\section{المفهوم الإجرائي للبحث}

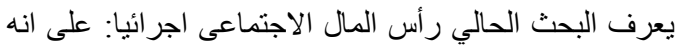

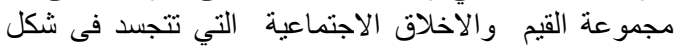

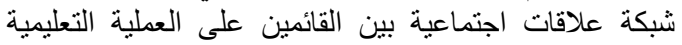

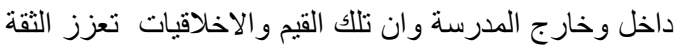

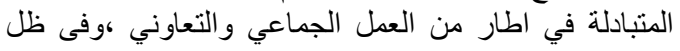

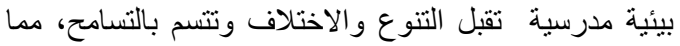
يساهم فى مو اجهة وحل المشكلات و التحديات . لئل

أثكال رأس المال الاجتماعي اهتمت العديد من الدراسات بتوضيح الأنواع المختلفة بمفهوم 


\section{المنهج البحثي}

أجري هذا البحث علي بس مبحوثاً من أعضاء مجالس الامناء

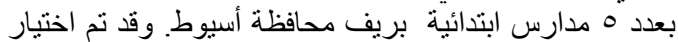

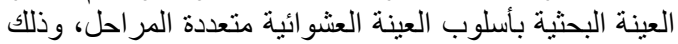

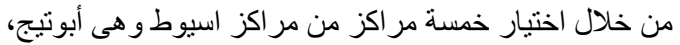

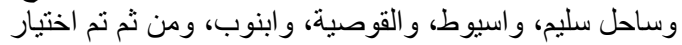
مدرسة بكل مركز. وتم ودمع وطع البيانات بو اسطة استمارة استبيان

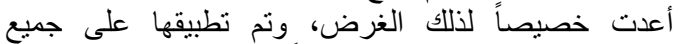

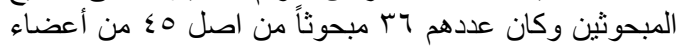

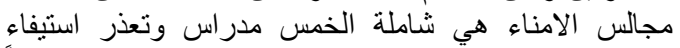
الاستبيان من باقي المبحوثين. وقد تم تصميم الاستبيان وفقاً

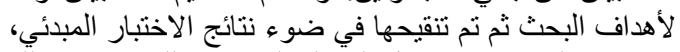

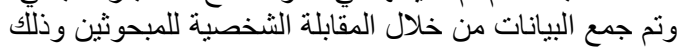

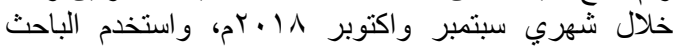
برنامج الحزمة الإحصائية للعلوم الاجتماعية (SPSS) في الإنيات

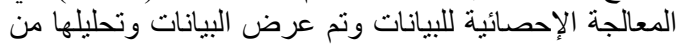

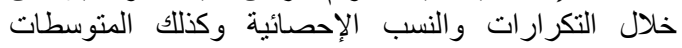
الحسابية والانحرافات المعيارية لتحقيق الهدف من الإنية البحثي.

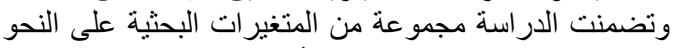

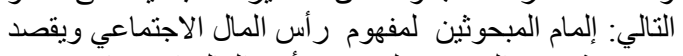

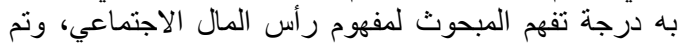

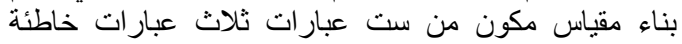
وثثلاث عبار ات صحيحة لتصنيف إلمام المبحوثين لمفهوم راس عاس

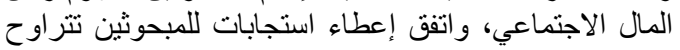

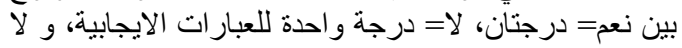

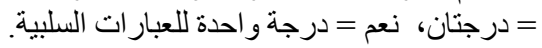

\section{أبعاد رأس المال الاجتماعي}

رأس المال الاجتماعي : وهو يشير حيث يشير إلى كمية

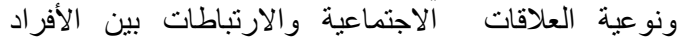

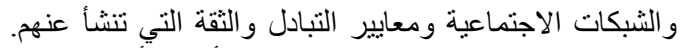

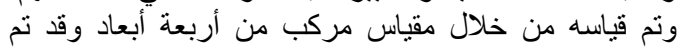

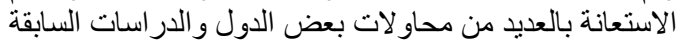

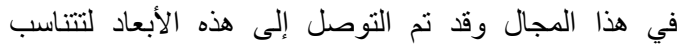
وموضوع البحث الحالي وهي:

ا. شبكة العلاقات الاجتماعية ونتير إلى طبيعية العلاقات

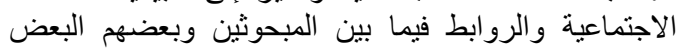

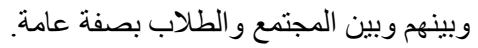

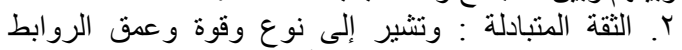

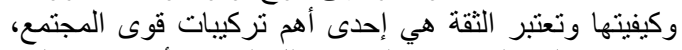
ومن غير الثقة العامة بين الناس يتحلل المجتمع أو يفقد تكامله.

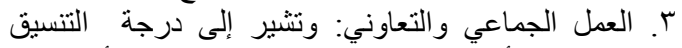

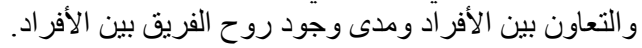

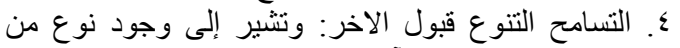

العدالة و الثفافية وقبول الآخر وانتشار قيم التسامح و المحبة.

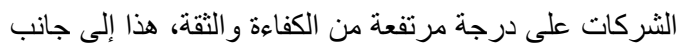

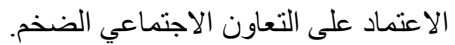

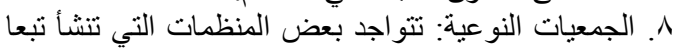

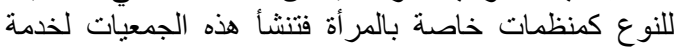
أشخاص معينة. 9. المجتمع المدني: ويتضمن المنظمات غير الحكومية والتي

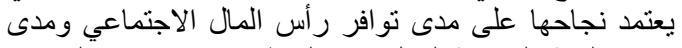

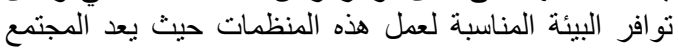

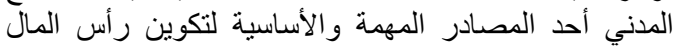

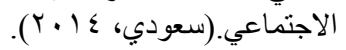

\section{قياس رأس المال الاجتماعي}

قدمت ساندرا فرانك نماذج متعددة لقياس رأس المال الاجتماعى بعد قراعتها لعدد من التجارب فئى فئ هذا السياق.

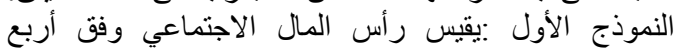

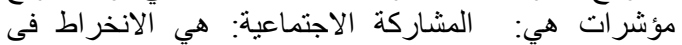

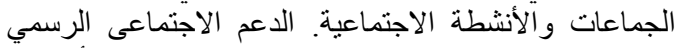

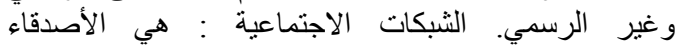

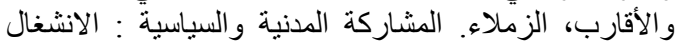

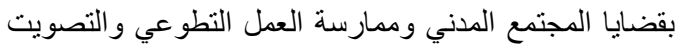

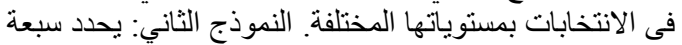

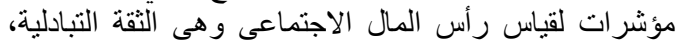

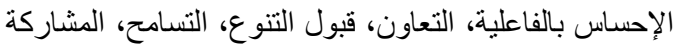

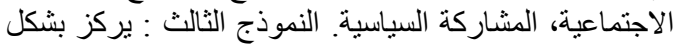

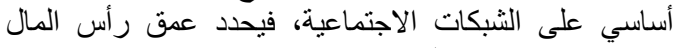

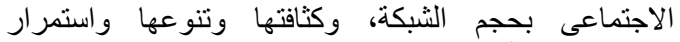

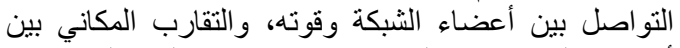

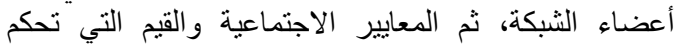

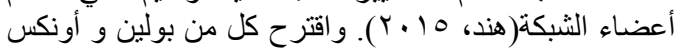
(Y. . V V)

$$
\begin{aligned}
& \text { I. المشاركة على مستوي المجتمع المحلي. } \\
& \text { r. بر المُ المبادرة في السياق الاجتماعي. } \\
& \text { r. ب. عشاعر الثقة والأمان. } \\
& \text { ع. علاقات الجيرة. } \\
& \text { ه. علاقات الأهل والأصدقاء. }
\end{aligned}
$$

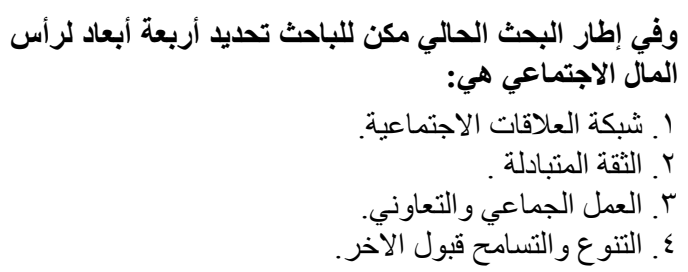




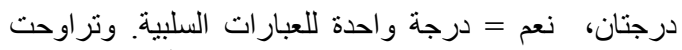

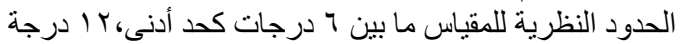

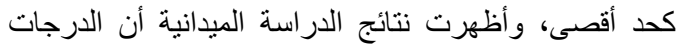

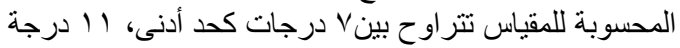

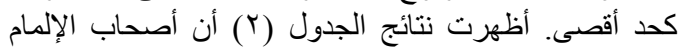

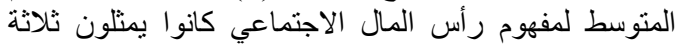

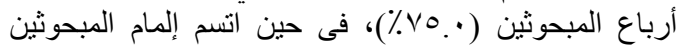

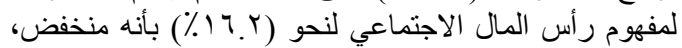

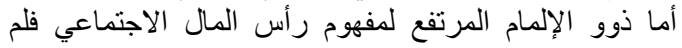

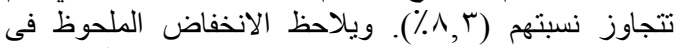

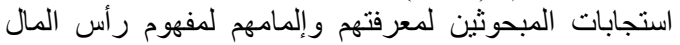

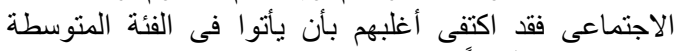

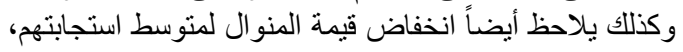

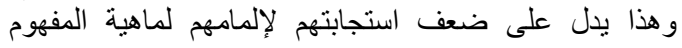

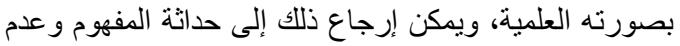
تداوله على نطاق و اسع.

\section{التتائج ومناقشتها}

أولا: إلمام المبحوثين بمفهوم رأس المال الاجتماعي

يشير الجدول (1) أن منوسطات عبارات إلمام المبحوثين

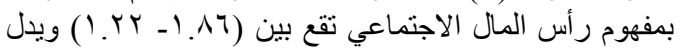

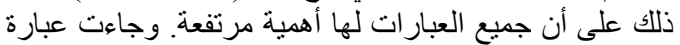

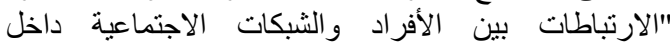

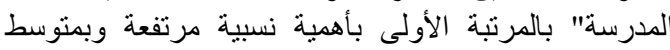

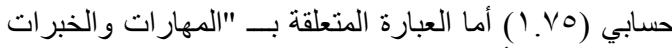

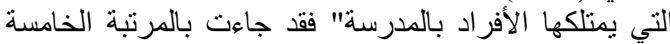

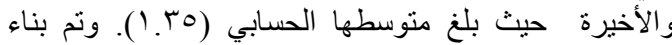

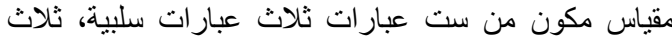

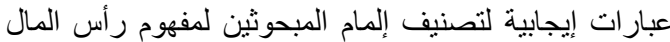

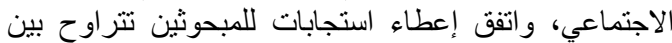

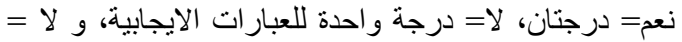

جدول (1): التوزيع العددي و النسبي لاستجابات المبحوثين طبقا لإلمامهم لمفهوم رأس المال الاجتماعى لمجلس الامناء.

\begin{tabular}{|c|c|c|c|c|c|c|c|c|}
\hline \multirow{2}{*}{ 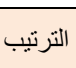 } & \multirow{2}{*}{ الحسابي } & \multicolumn{2}{|c|}{ الإجمالي } & \multicolumn{2}{|c|}{$\mathrm{y}$} & \multicolumn{2}{|c|}{ 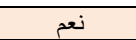 } & \multirow{2}{*}{ المقصود بمفهوم رأس المال الاجتماعى } \\
\hline & & $\%$ & عدد & $\%$ & عدد & $\%$ & عدد & \\
\hline$\varepsilon$ & $1 . \leqslant V$ & $1 \cdots \cdot$ & $r 4$ & or.A & 19 & 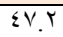 & IV & ما يمتلكه العاملون بالمدرسة من امو ال او عقار ات \\
\hline 0 & $1 . r$. & $1 \cdots$ & דיץ & $79 . \varepsilon$ & ro & $r \cdot .7$ & 11 & مقدار من المو ارد الطبيعية بالمدرسة \\
\hline 7 & T.KY & $1 \cdots \cdot$ & rq & VV.A & $\overline{Y \Lambda}$ & YY.Y & $\Lambda$ & المهار ات والخبرات التي يمتلكها الأفر اد بالمدرسة \\
\hline 1 & $1 . \wedge 7$ & $1 \cdots$ & ד & $1 \Gamma .9$ & 0 & 入५. 1 & T) & الارتباطات بين الأفر اد و آلَّبكات الاجتماعية داخل المدرسة \\
\hline Y & I.A. & $1 \cdots \cdot$ & T4 & 19.5 & $\mathrm{~V}$ & $\lambda \cdot .7$ & rq & معايير التبادل و الثقة بين العاملين بالمدرسة \\
\hline$r$ & 1.77 & $1 \cdots$ & ז & rT.r & IT & $77 . \mathrm{Y}$ & $r \varepsilon$ & كمية ونو عية العلاقات الاجتماعية بين الأفر اد بالمدرسة \\
\hline
\end{tabular}

جدول (r): التوزيع العددي و النسبي للمبحوثين طبقا لإلمامهم المبحوثين لمفهوم رأس المال الاجتماعي لمجلس الامناء.

\begin{tabular}{|c|c|c|}
\hline النسبة المئية & عدد & مستوى الإلمام \\
\hline$\Lambda . r$ & $r$ & مرتفع \\
\hline Vo. & TV & متوسط \\
\hline 17.8 & 7 & منخفض \\
\hline $1 \cdots \cdot$ & rq & الإجمالي \\
\hline
\end{tabular}

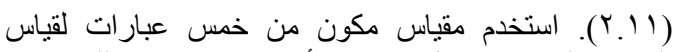

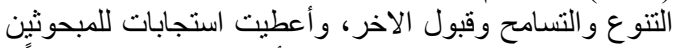

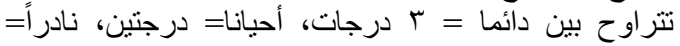

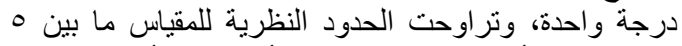

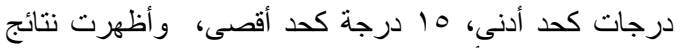

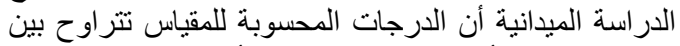

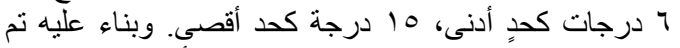

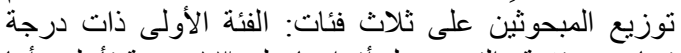

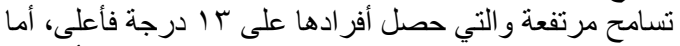

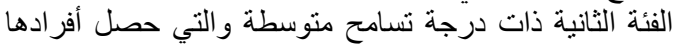

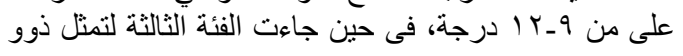

ثانيا: أبعاد رأس المال الاجتماعى

ا ـ البعد الأول: التنوع والتسامح وقبول الآخر

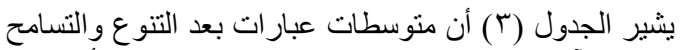

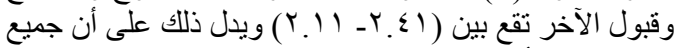

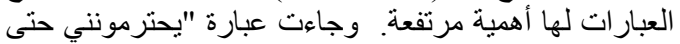

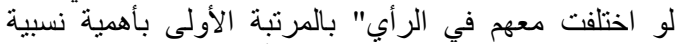

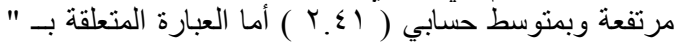

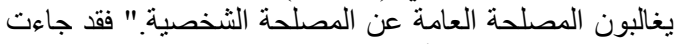
بالمرتبة الخامسة والأخيرة حيث بلغ متوسطها الحسابي لخئ 
بدرجة متوسطة فكانوا يمثلون أكثر من النصف المبحوثين

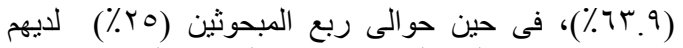
استجابة منخفضة لبعد التسامح من إجمالي عد عد المبحوثين.
درجة التسامح المنخفضة والتي حصل أفر ادها على م درجات

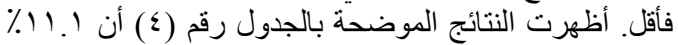

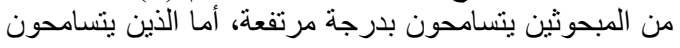

جدول (־)): التوزيع العددي و النسبي لاستجابات المبحوثين طبقا لإلمامهم لمفهوم رأس المال الاجتماعى لمجلس الامناء.

\begin{tabular}{|c|c|c|c|c|c|c|c|c|}
\hline \multirow{2}{*}{ 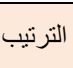 } & \multirow{2}{*}{ المسابي } & \multicolumn{2}{|c|}{ 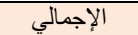 } & \multicolumn{2}{|c|}{$\bar{y}$} & \multicolumn{2}{|c|}{ نعم } & \multirow{2}{*}{ المقصود بمفهوم رأس المال الاجتماعى } \\
\hline & & $\%$ & عدد & $\%$ & عدد & $\%$ & عدد & \\
\hline$\varepsilon$ & $1 . \leqslant V$ & $1 \cdots \cdot$ & ry & or.1. & 19 & $\sum V_{\text {.Y }}$ & IV & ما يمتلكه العاملون بالمدرسة من اموال او عقار ات \\
\hline 0 & $1 . r$. & $1 \cdots$ & rq & $79 . \varepsilon$ & TO & $r \cdot .7$ & 11 & مقدار من الموارد الطبيعية بالمدرسة \\
\hline 7 & I.YY & $1 \cdots \cdot$ & ry & $V^{V} . \wedge$ & YA & YY. & $\wedge$ & المهار ات و الخبر ات التي يمتلكها الأفر اد بالمدرسة \\
\hline 1 & $1 . \wedge 7$ & $1 \cdots$ & rq & 15.9 & 0 & 人.. 1 & r) & الارتباطات بين الأفر اد و التُشبكات الاجتماعية داخل المدرسة \\
\hline r & $1 . \wedge$. & $1 \cdots \cdot$ & rq & $19 . \varepsilon$ & $\mathrm{V}$ & A. .7 & rq & معايير التبادل و الثقة بين العاملين بالمدرسة \\
\hline$r$ & 1.77 & $1 \cdots \cdot$ & rq & rT.r & 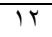 & $77 . \mathrm{V}$ & $T \leq$ & كمية ونو عية العلاقات الاجتماعية بين الأفر اد بالمدرسة \\
\hline
\end{tabular}

جدول (ع): التوزيع العددي و النسبي للمبحوثين طبقا لإلمامهم المبحوثين لمفهوم رأس المال الاجتماعي لمجلس الامناء.

\begin{tabular}{|c|c|c|}
\hline النسبة المئية & عدد & مستوى الإلمام \\
\hline$\wedge . r$ & $r$ & مرتفع \\
\hline Vo.. & TV & متوسط \\
\hline 17.8 & 7 & منخفض \\
\hline $1 \cdots \cdot$ & $r 4$ & الإجمالي \\
\hline
\end{tabular}

\section{r. البعد الثالث: شبكة العلاقات الاجتماعية}

يثير الجدول (V) أن متوسطات عبارات بعد شبكة

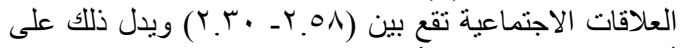

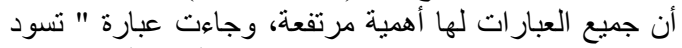

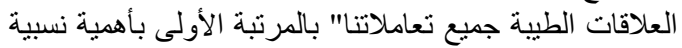

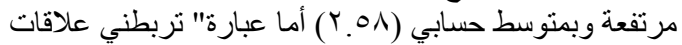

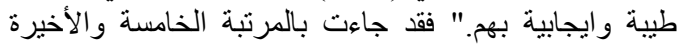

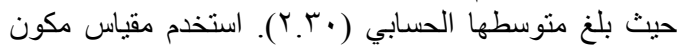

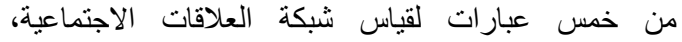

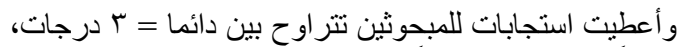

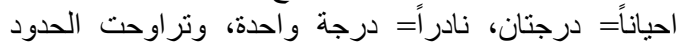

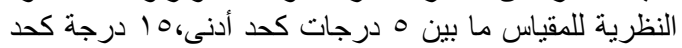

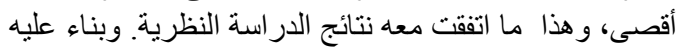

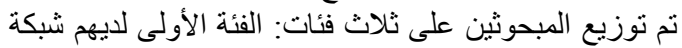

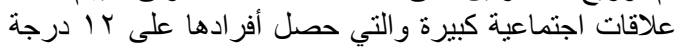

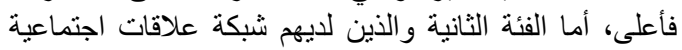

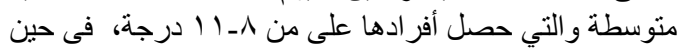

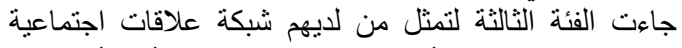

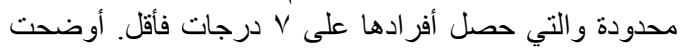

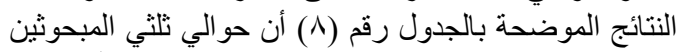

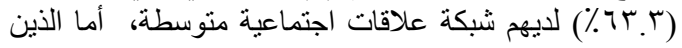

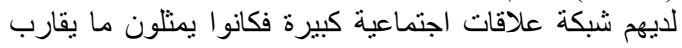
من الثلث (7. • ب\%) من إجمالي المبحوثين، في حين لم تتجاوز

\section{r. البعد الثاني: الثقة المتبادلة}

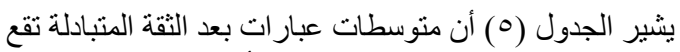

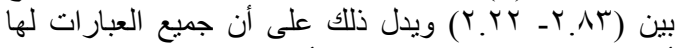

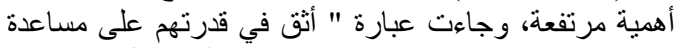

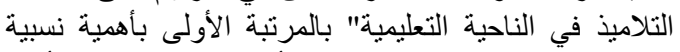

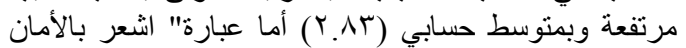

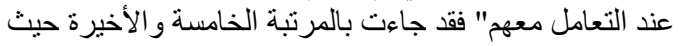

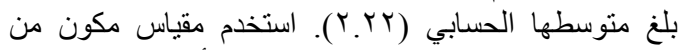

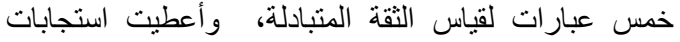

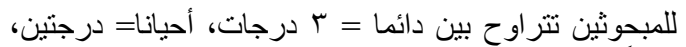

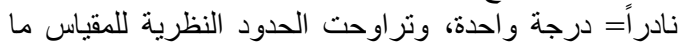

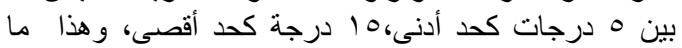

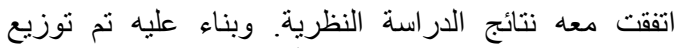

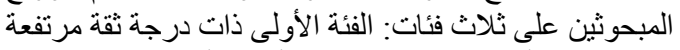

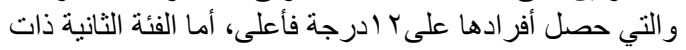

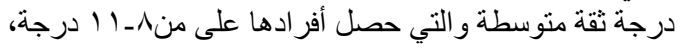

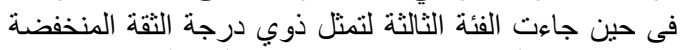

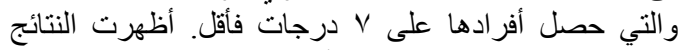

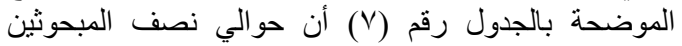

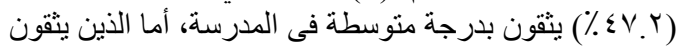

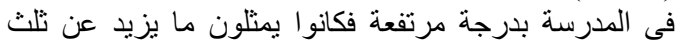

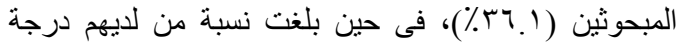

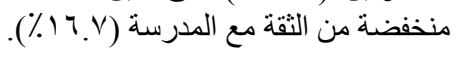


Rashed et al. / Archives of Agricultural Sciences Journal 2(3) 27-37, 2019.

نسبة من لديهم شبكة علاقات اجتماعية محدودة مع أولياء الأمور (7.0\%).

جدول (0): التوزيع العددي و النسبي لاستجابات المبحوثين طبقا لبعد الثقة المتبادلة لمجلس الامناء.

\begin{tabular}{|c|c|c|c|c|c|c|c|c|}
\hline \multirow{2}{*}{ 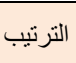 } & \multirow{2}{*}{ الحسابي } & \multicolumn{2}{|c|}{ الإجمالى } & \multicolumn{2}{|c|}{$\bar{\gamma}$} & \multicolumn{2}{|c|}{ نعم } & \multirow[b]{2}{*}{ 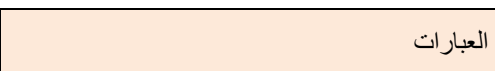 } \\
\hline & & $\%$ & عدد & $\%$ & عدد & $\%$ & عدد & \\
\hline $1 \ldots$ & rצ & A.r & r & rer & Tr & $O \Lambda .{ }^{\prime}$ & Y) & أثثق في قدر تهر على مساعدة التلاميذ في الناحبة التعليمية \\
\hline $1 \cdots \cdot$ & צו & 11.1 & $\varepsilon$ & r..1 & Tr & 0 or.1 & 19 & استشير هم في حالة وجود مشكلة ما لأبنائي \\
\hline $1 \cdots$ & rq & $17 . \mathrm{V}$ & 7 & $\varepsilon \varepsilon . \varepsilon$ & 17 & rᄉ. 9 & $1 \varepsilon$ & اشعر بالأمان عند التعامل معهر \\
\hline $1 \cdots \cdot$ & rq & $17 . \mathrm{V}$ & 7 & YY.A & 1. & 00.7 & $r \cdot$ & بعاملون على تعزيز العلاقة فيما بيننا \\
\hline $1 \cdots$ & rq & $1 \% .9$ & 0 & $\varepsilon 1 . \mathrm{V}$ & 10 & $\varepsilon \varepsilon$. & 17 & يحر صون على وجو د تبادل للخبر ات بيننا \\
\hline
\end{tabular}

جدول (؟): التوزيع العددي و النسبي للمبحوثين طبقا لدرجة الثقة المتبادلة لمجلس الامناء.

\begin{tabular}{|c|c|c|}
\hline النسبة المنئة & عدد ( عد & الثقة المتبادلة \\
\hline r.. & $\pi$ & مرتفع \\
\hline$\varepsilon V, Y$ & IV & متو سط \\
\hline 17.8 & 7 & منخفض \\
\hline $1 \cdots$ & ry & الإجمالي \\
\hline
\end{tabular}

جدول (V): التوزيع العددي و النسبي لاستجابات المبحوثين طبقا لبعد شبكة العلاقات الاجتماعية لمجلس الامناء.

\begin{tabular}{|c|c|c|c|c|c|c|c|c|}
\hline \multirow{2}{*}{ 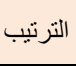 } & \multirow{2}{*}{ الحسابي } & \multicolumn{2}{|c|}{ الإجمالي } & \multicolumn{2}{|c|}{ y } & \multicolumn{2}{|c|}{ نعم } & \multirow{2}{*}{ 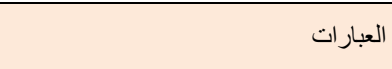 } \\
\hline & & $\%$ & عدد & $\%$ & عدد & $\%$ & عدد & \\
\hline $1 \cdots$ & ry & 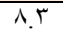 & $r$ & ro. & 9 & $77 . \mathrm{V}$ & $r \varepsilon$ & اظن إنني اعرف كل من بالمدرسة \\
\hline $1 \cdots \cdot$ & ry & $1 \pi .9$ & 0 & re.r & Ir & Or.1 & 19 & يوجد بينا تو اصل دائم داخل وخار ج المدرسة \\
\hline $1 \cdots$ & rq & 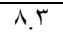 & $r$ & r^.9 & $1 \varepsilon$ & 0 Or.1 & 19 & تسود العلاقات الطيية جميع تعاملاتنا \\
\hline $1 \ldots$ & r4 & r.A & 1 & $0 .$. & 11 & $\varepsilon V, Y$ & IV & يوجد فيما بيننا حوار بناء قدر الامكان \\
\hline $1 \cdots \cdot$ & rq & A.T & $\Gamma$ & or.A & 19 & rA.9 & Tई & تربطني علاقات طيبة و إيجابية بهم \\
\hline
\end{tabular}

جدول (^): التوزيع العددي و النسبي للمبحوثين طبقا لبعد شبكة العلاقات الاجتماعية لمجلس الامناء.

\begin{tabular}{|c|c|c|}
\hline النسبة المئية & عدد & شبكة العلاقات الاجتماعية \\
\hline$r \cdot .7$ & 11 & مرتفع \\
\hline 74.9 & Tr & متوسط \\
\hline 0.7 & r & منخفض \\
\hline $1 \cdots \cdot$ & rq & الإجمالي \\
\hline
\end{tabular}

وأظهرت نتائج الدراسة الميدانية أن الدرجات المحسوبة

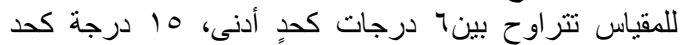

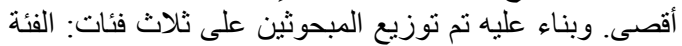

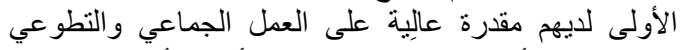

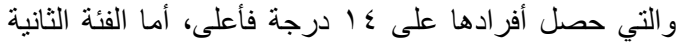

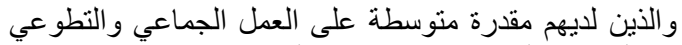

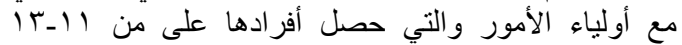

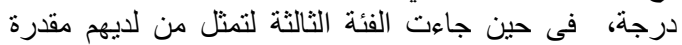
منخفضة على العمل الجماعي والتطوعي مع أولياء الأمور

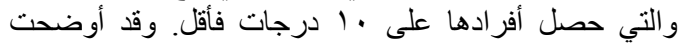

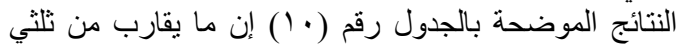

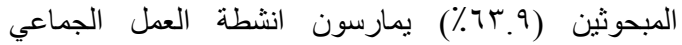
والتطوعي بدرجة مرتفعة، اما الذين يمارسون انشطة العمل
ع. البعد الرابع: العمل الجماعي والتطوعي

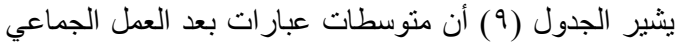

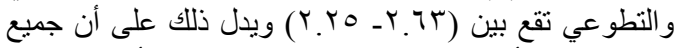

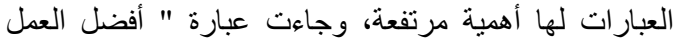

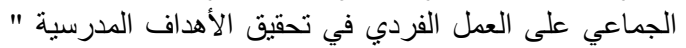

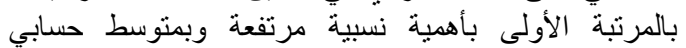

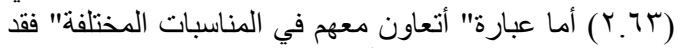

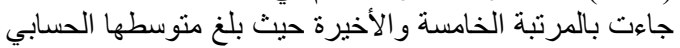

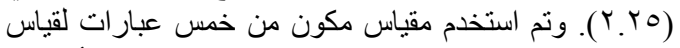

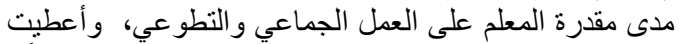

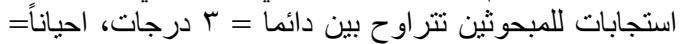

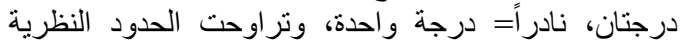
للمقياس ما بين ه درجات كحد أدنى، 10 درجة ورجة كحد أقصى، 


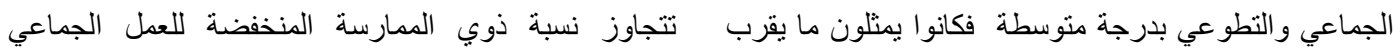

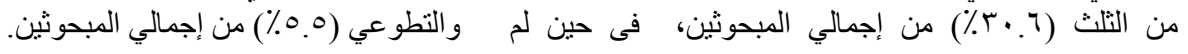

جدول (9): التوزيع العددي و النسبي لاستجابات المبحوثين طبقا لبعد شبكة العلاقات الاجتماعية لمجلس الامناء.

\begin{tabular}{|c|c|c|c|c|c|c|c|c|}
\hline \multirow{2}{*}{ الترتيب } & \multirow{2}{*}{ الحسابي } & \multicolumn{2}{|c|}{ الإجمالي } & \multicolumn{2}{|c|}{$y$} & \multicolumn{2}{|c|}{ نعم } & \multirow{2}{*}{ 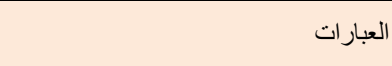 } \\
\hline & & $\%$ & عدد & $\%$ & عدد & $\%$ & عدد & \\
\hline $1 \cdots \cdot$ & $r$ & A.r & $r$ & ro.. & 9 & $77 . \mathrm{V}$ & $r \varepsilon$ & اظن إنني اعرف كل من بالمدرسة \\
\hline $1 \cdots$ & ry & 15.9 & 0 & re.r & Tr & 0 or.1 & 19 & يوجد بينا تو اصل دائم داخل وخار ج المدرسة \\
\hline $1 \cdots \cdot$ & ry & А. ${ }^{2}$ & r & rᄉ. 9 & $1 \varepsilon$ & 0 or.A & 19 & تسود العلاقات الطيبة جميع تعاملاتتا \\
\hline $1 \cdots \cdot$ & r4 & r.A & 1 & $0 . . \cdot$ & 11 & $\varepsilon Y, Y$ & IV & يوجد فيما بيننا حوار بناء قدر الامكان \\
\hline $1 \cdots \cdot$ & r4 & A.r & r & or.A & 19 & $r \Lambda .9$ & $1 \varepsilon$ & تربطني علاقات طيية و إيجابية بهم \\
\hline
\end{tabular}

جدول (• ( ): التوزيع العددي والنسبي للمبحوثين طبقا لبعد شبكة العلاقات الاجتماعية لمجلس الامناء.

\begin{tabular}{|c|c|c|}
\hline النسبة المئية & عدد & شبكة العلاقات الاجتماعية \\
\hline$r \cdot .7$ & 11 & مرتفع م \\
\hline 74.9 & Tr & متوسط \\
\hline 0.7 & $r$ & منخفض \\
\hline $1 \cdots \cdot$ & r4 & الإجمالي \\
\hline
\end{tabular}

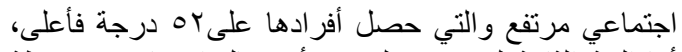

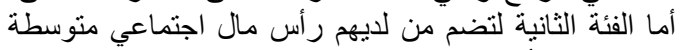

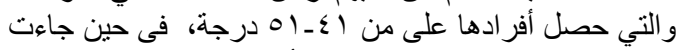

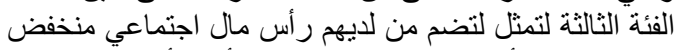

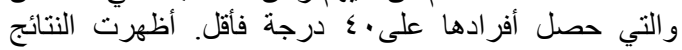

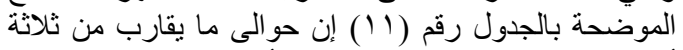

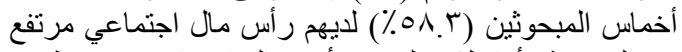

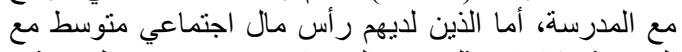

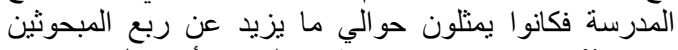
(\%.^)

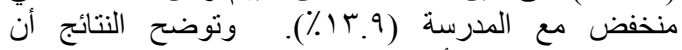

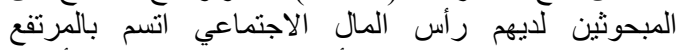
و المتوسط، وعليه فإننا نستنتج أن ثمة علاقات جيدة بين أولياء الأمور والمدرسة.

\author{
๑ـ البعد الخامس: رأس المال الاجتماعي الإجمالي \\ وقد تم حسابه من خلال جمع متوسط استجابات المبحوثين فى لإنى \\ الأبعاد الأربعة لر أس المال الاجتماعي: \\ أـ التسامح والتنوع وقبول الآخر. \\ بـ الثقة المتبادلة. \\ ت- حجم شبكة العلاقات الاجتماعية. \\ ج- العمل الجماعي و التطوعي.
}

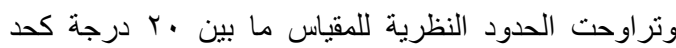

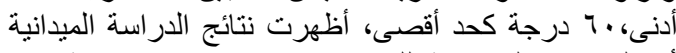

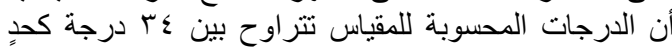

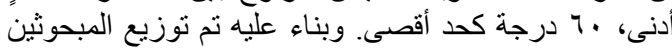
على ثلاث فئات: الفئة الأولى لتضم من لايهم رأس مأس مال

جدول (1 (1): التوزيع العددي و النسبي للمبحوثين طبقا لإجمالي رأس المال الاجتماعى لمجلس الامناء.

\begin{tabular}{|c|c|c|}
\hline النسبة المئية & عدد & رأس المال الاجتماعي \\
\hline $0 \wedge . r$ & YI & مرتفع \\
\hline TV.A & 1. & متوسط \\
\hline 11.9 & 0 & منخفض \\
\hline $1 \cdots \cdot$ & ry & الإجمالي \\
\hline
\end{tabular}

مرتبة تنازلياً حسب موافقتهم على تلك العبار ات كما تصور ها

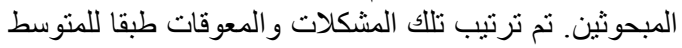

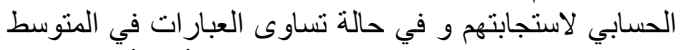

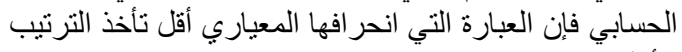

تكوين وزيادة رأس المثلال الاجتماعوقي بالمدرسية تؤثر على

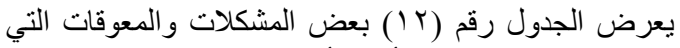
تؤثر على تكوين وزيادة تأثير رأس المال الاجتماعي بالمدرسة 
Rashed et al. / Archives of Agricultural Sciences Journal 2(3) 27-37, 2019.

جدول (r ( ): بعض المشكلات والمعوقات التي تثؤثر على تكوين وزيادة تأثير رأس المال الاجتماعى بالمدرسة.

\begin{tabular}{|c|c|c|c|c|c|c|c|c|c|c|}
\hline \multirow{3}{*}{ الترتيب } & \multirow{3}{*}{ المعياري } & \multirow{3}{*}{ الحسابي } & \multirow{3}{*}{ المرجمح } & \multicolumn{6}{|c|}{ الاستجابات } & \multirow{3}{*}{ 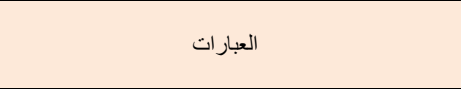 } \\
\hline & & & & \multicolumn{2}{|c|}{ 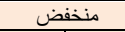 } & \multicolumn{2}{|c|}{ متوسط } & \multicolumn{2}{|c|}{ عالي } & \\
\hline & & & & $\%$ & ك & $\%$ & 5 & $\%$ & s & \\
\hline 9 & 00. & T. $\leqslant$ & $\Lambda \Lambda$ & T.A & $T$ & $0 . . \cdot$ & 11 & $\sum V, Y$ & TV & قلمقلة الوعى بأهمية رأس المال الاجتماعي \\
\hline IT & $0 \leqslant$. & t. TA & 14 & r.A & 1 & $\varepsilon 1 . \gamma$ & 10 & 00.1 & r. & انتثار علاقات الثكك وضعف الثقة المتبادلة بين الافراد \\
\hline 1 & 01. & T.VY & 91 & T.A & $T$ & TY.Y & A & Vo. & $T V$ & يادة كثافة الفصول \\
\hline $\mathrm{A}$ & $7 \cdot \cdot$ & Y. $\leqslant \mathrm{V}$ & 19 & 0.1 & r & $\xi 1 . \gamma$ & 10 & 0 or.1 & 19 & الثقليل من اهمية العمل التطو عي \\
\hline 7 & $7 \cdot . \cdot$ & Y.OY & 91 & 0.7 & r & T4.1 & ir & $01 . r$ & r) & تدنى مرتبات العاملين بالمنظومة التعليمبة وبخاصة المعلمين \\
\hline T & or.. & $r .77$ & 97 & T.A & 1 & $r Y . A$ & 1. & $79 . \varepsilon$ & To & ضعف العلاقة بين المدرسة و المجتمع المحلى \\
\hline o & $7 .$. & T.00 & $\overline{Q T}$ & 0.7 & $\bar{Y}$ & rT.r & IT & 71.1 & $\overline{T Y}$ & علم وجود لغة حوار بين جميع أطر اف العملية التعليمية \\
\hline 1. & $7 \cdot$. & T. $\leftleftarrows \varepsilon$ & $\mathrm{A \Lambda}$ & 0.7 & Y & ๕๕.६ & 17 & $0 .$. & $1 \mathrm{in}$ & |نتشار قيم الانانية و النز عة الفردية \\
\hline $1 \varepsilon$ & $v \cdot . \cdot$ & T.r. & AT & 15.9 & o & $\leqslant 1 . \mathrm{V}$ & 10 & 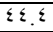 & 17 & ل تفشى السلبية و اللامبالاة والانعز الية \\
\hline II & 70. & T. $\leqslant$ & $\mathrm{AN}$ & A.r & $\mu$ & $r \wedge .9$ & $1 \leqslant$ & $0 Y .1$ & 19 & قتص الامكانيات المادية لدى المدرسة \\
\hline$\varepsilon$ & 00. & T.00 & 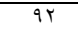 & T.A & 1 & $r \Lambda .9$ & $1 \varepsilon$ & 01.5 & Tr & ضِعف الكفاءة الادارية داخل المدرسة \\
\hline$r$ & Tะ. & T.01 & 94 & 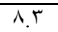 & $r$ & To. & 9 & 77.7 & $T \leqslant$ & ضِعف التنسيق بين المنظمات المختلفة بالقرية و المدرسة \\
\hline ir & TV. & T.rT & $\Lambda \varepsilon$ & 11.1 & $\xi$ & 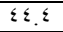 & 17 & 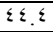 & 17 & يكتثاتورية الإدارة وتسلطها \\
\hline $\mathrm{Y}$ & $0 . \cdot$ & T.O. & q. & $\because \cdot$ & . & $0 . .0$ & 11 & $0 . \cdot$ & $1 \mathrm{in}$ & انتشار الاسلوب المركزي في الادارة \\
\hline 10 & 79. & T. YO & A1 & 15.9 & o & $\sum \mathrm{E}, \mathrm{Y}$ & IV & $r \Lambda .9$ & $1 \leqslant$ & لئطء الحر الك المهني للقيادات التعليمية \\
\hline
\end{tabular}

وتم تتقيحها واختيار المناسب منها وتم عرض بعضها و التي

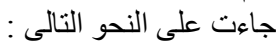

ا ا ـ استخدام وسائل التعلم النشط مثل التبل السبورة التفاعلية.

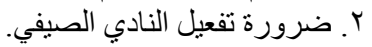
r. الا هتمام بالتتمية المهنية المستدامة لفيل للمعلمين. ع. ــ مر اعاة الفروق بين التلاميذ. ๑. وجود نظام ربط الإلكتروني بين المدراس على على مستوى المحافظة. 7. تتمية روح التعاون و التنافس وليس الصراع بين المدر اس البع

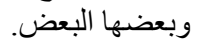

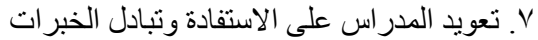

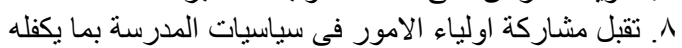

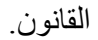

\section{التوصيات}

ا. العمل على تفعيل مجلس الامناء لزيادة درجة المشاركة

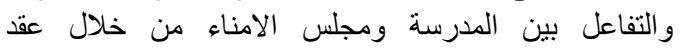

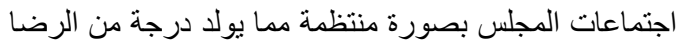
و الثقة. r. العمل على محاربة الدروس الخصوصية من خلال عودة نظام مجمو عات التقوية المدرسية.

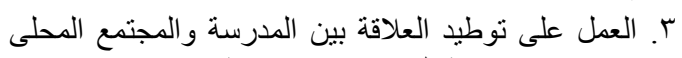
وتوسيع وتعميق شبكة العلاقات الاجتماعية بينهما.

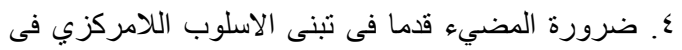

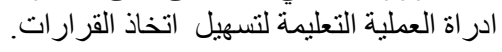

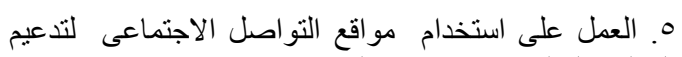

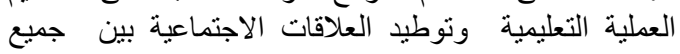
الاطر اف المرتبطة بالعلمية التعلمية.

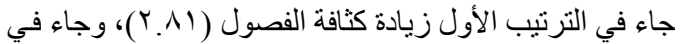

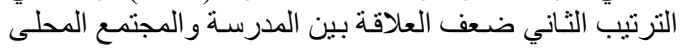

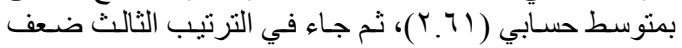

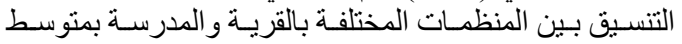

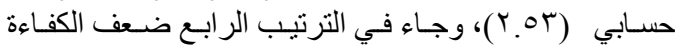

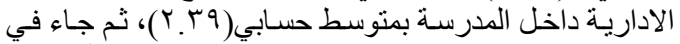

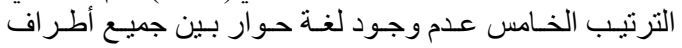

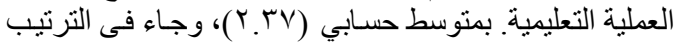

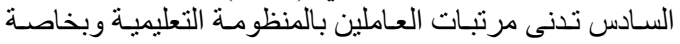

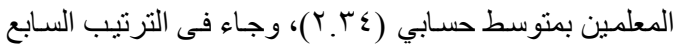

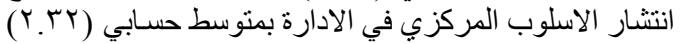

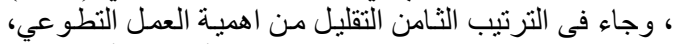

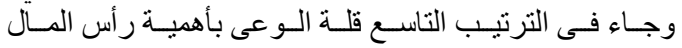

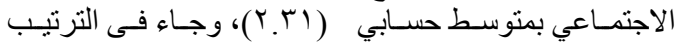

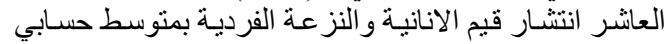

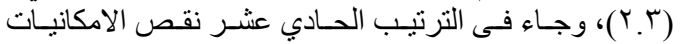

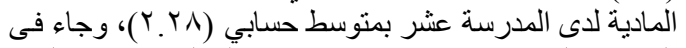

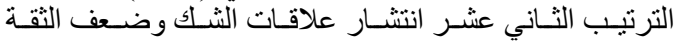

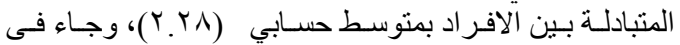

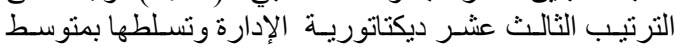

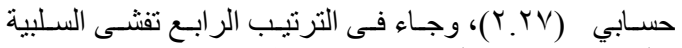

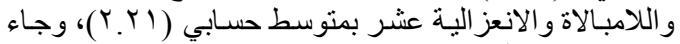

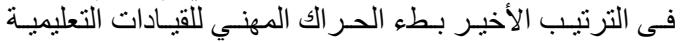
بمتوسط حسابى (19 (Y. (Y).

\section{رابعا: مقترحات تساعد على تكوين وزيادة تأثير رأس المال الاجتماعي بالمدرسة}

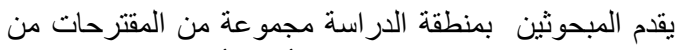

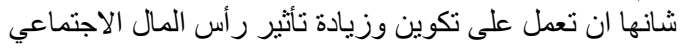
بالمدرسة وذللك من خلال طرح سؤ ال مفتوح عن مقترحاتهر الثاني 


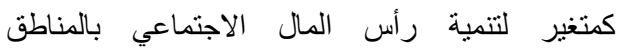

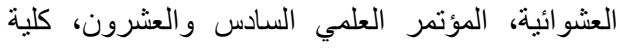

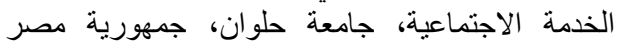

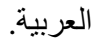

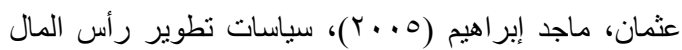

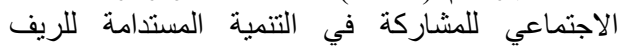

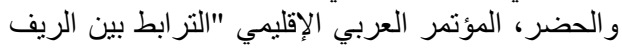

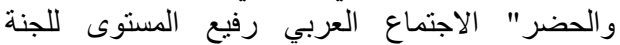

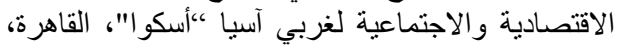

$$
\text { جمهورية مصر العربية. }
$$

أبو زاهر، نادية (• • (Y)، محاولة لفهم إنثكالية رأس المال

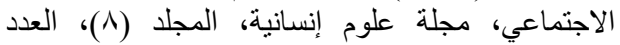

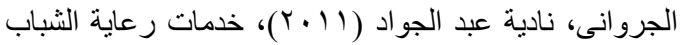

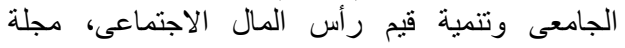

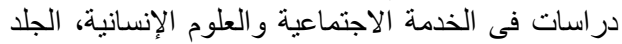

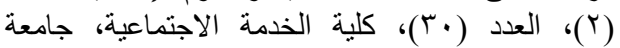
حلوان، جمهورية مصر العربية.

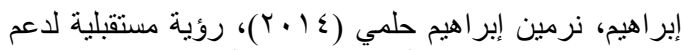

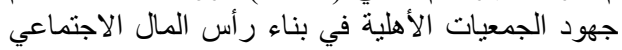

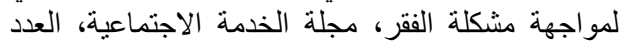

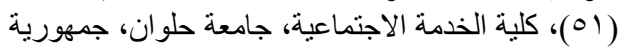

$$
\text { مصر العربية. }
$$

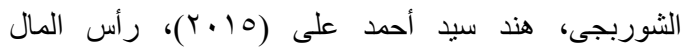

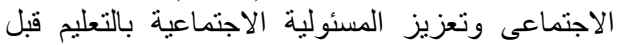

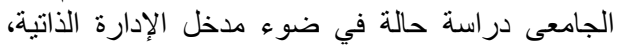

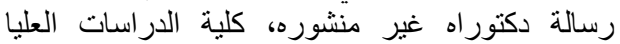
للتربية، جامعة القاهرة، جمهورية مصر العربية.

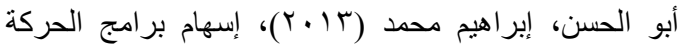

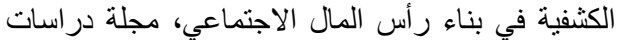

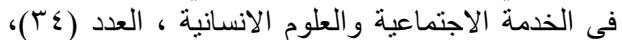
الجزء (1)، جمهورية مصر العربية.

حمزة، أحمد إبراهيم (10 بالب)، العمل الاجتماعى التطوعي "الو اقع و المأمول"، دار المسيرة للنشر والتوزيميع، عمان.

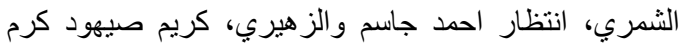

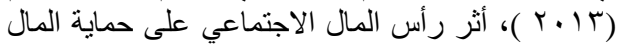

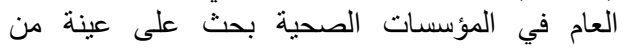
المؤسسات الصحية في دائرة صحة ديالى العئ ، مجلة الإدارة

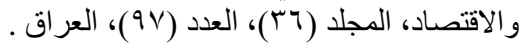

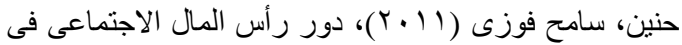

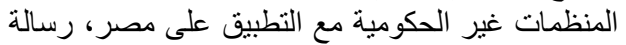
ماجستير غير منشوره، كلية الاقتصاد و العلوم السياسية، جامعة القاهرة، جمهورية مصر العرة الأعربية.

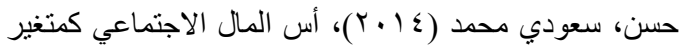

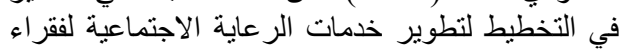

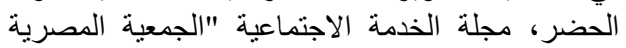

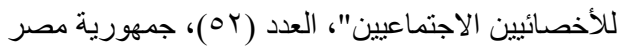

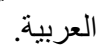

العطوى، عامر علي حسين (9 ج . ب)، العلاقة بين رأس المال

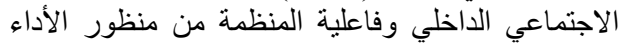

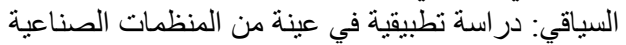

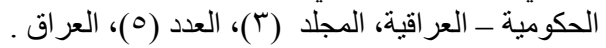

عبد الجليل، عصام محمد طلعت (T + r)، المشاركة المدنية 